\title{
An Approach for Prioritization of State Highways and Its Application
}

\author{
Sudipta Pal ${ }^{1} \cdot$ Bhargab Maitra $^{2} \cdot$ J. R. Sarkar ${ }^{2}$
}

Received: 7 November 2015/Accepted: 26 May 2016/Published online: 11 June 2016

(C) Springer International Publishing Switzerland 2016

\begin{abstract}
The present paper documents a rational approach for prioritization of road sections with reference to fifteen State Highway sections in the State of West Bengal in India. The work demonstrates an opportunity for policy makers to identify various sections which may be taken up for improvement using the fund obtained from various schemes and prioritize them. Seven techno-economic factors are considered for prioritization and the weightages for these factors are obtained by analysing the rating data using Technique for Order Preference by Similarity to Ideal Solution (TOPSIS) and RIDIT method. In the absence of usable accident data, the potential safety hazard is considered as a techno-economic factor in the prioritization. The potential safety hazard is estimated on the basis of identified causal factors and their relative weightages are derived from the analysis of expert opinion data using Analytic Hierarchy Process (AHP). Although the results presented in the paper are case specific, but the approach documented in the paper may be modified suitably to prioritize roads in other geographical regions.
\end{abstract}

Keywords Prioritization - Techno-economic factors · Strategic factors $\cdot$ Rating analysis $\cdot$ TOPSYS $\cdot$ AHP

Sudipta Pal

spalonline@ rediffmail.com

Bhargab Maitra

bhargab@civil.iitkgp.ernet.in

J. R. Sarkar

jrsarkar@gmail.com

1 Highway Division Kolkata, RITES Ltd, 56 CR Avenue, Kolkata 700012, West Bengal, India

2 Department of Civil Engineering, IIT Kharagpur, Kharagpur 721302, West Bengal, India

\section{Introduction}

India has taken up numerous initiatives to upgrade its road infrastructure. At the National level, several ambitious projects have been taken-up through National Highways Authority of India (NHAI) primarily to upgrade the National Highways which are considered as the backbone of the Nation. Over the last decade, National Highways have improved significantly due to implementation of several projects related to strengthening and/or widening of 2-lane roads to 4-lane/6-lane dual carriageway standards. Following the success of the NHAI, several dedicated road development corporations have also been formed at State levels for improvement of State Highways (SH). The funds available to State Road Development corporations are generally limited as compared to the length of State Highways which need improvement. Therefore, it is necessary to prioritize SH sections and carry out initial selection of SH sections for improvement as per the priority. Once road sections are selected as per the prioritization, feasibility study may be carried out to identify the most suitable improvement option commensurate with available funding and then a detailed project report may be prepared before execution of the recommended improvement proposal. It may also be mentioned that often funds for development of SH sections are available with specific focus areas such as Backward Region Grant Fund, Border roads development fund, etc. It is therefore, important to identify the SH sections which are eligible to be considered under different focus area funding schemes and then select sections as per the priority for further detailed investigations and improvement.

Several works have been reported in the literature on prioritization in various contexts of road improvement. Chakroborty et al. [1] investigated comprehensive 
pavement maintenance strategies for road network through optimal allocation of resources. A tool was developed to allocate resources in an optimal manner so as to keep the road infrastructure as 'healthy' as possible. The tool acknowledged that maintenance needs are not only restricted to structural aspects but also extend to the functional and safety related aspects of a road. Ahmed [2] developed an analytical decision model for resource allocation in highway maintenance and management. Chan et al. [3] proposed a method for prioritized allocation of resources to maintenance activities and the maximum utilization of resources. It was demonstrated that the GA with the prioritized resource allocation method outperformed the traditional GA with repair or penalty methods. Ferreira et al. [4] demonstrated a segment-linked optimization model for deterministic pavement management systems. The model was aimed at determining the least-cost maintenance and rehabilitation strategy to be implemented in a road network, taking into account the applicable technical and budgetary constraints. Fwa et al. [5] developed a genetic algorithm based approach for solving multi objective network level pavement maintenance programming problems. Friesz et al. [6] determined quality of a facility by natural factors, rate of use and maintenance investments while demand for the facility was assumed to be a function of its quality. A dynamic optimization model in the form of a simple linear optimal control problem was developed in order to determine optimal maintenance policies under various circumstances. Ouyang and Madanat [7] suggested a mathematical programming model for optimal highway pavement rehabilitation planning to minimize the life-cycle cost for a finite horizon. The objective function of this model was to minimize in a finite horizon the discounted total life-cycle cost, including both user cost and agency cost. The facility condition at the end of planning horizon was constrained by a minimum serviceability requirement. Sinha et al. [8] described a mathematical programming procedure for routine maintenance activities at the network level. A priority-weighting factor was assigned to each maintenance work so that higher-priority work would be selected for execution. Rehabilitation constraints were included to ensure proper coordination between the selected routine maintenance activities and planned rehabilitation projects. It is evident from all these works that the influencing factors and methodology for prioritization are directly linked with the purpose or the context of prioritization. Also, the purpose or the context of prioritization in the present work is different from those which have been reported in the literature. With this background, the present paper aims to suggest a rational methodology for prioritization of SH sections which will be used for initial selection of road sections for carrying out feasibility study and preparation of detailed project report (DPR) as per available funding source. The work is demonstrated with reference to a few $\mathrm{SH}$ sections in the State of West Bengal in India.

The paper is organized in four sections. Section "Methodology" describes a rational methodology for prioritization of $\mathrm{SH}$ sections. It includes identification of techno economic factors, identification of strategic factors, importance of techno-economic factors in prioritization, importance of causal factors in potential safety hazard and estimation of priority index for each road section. Application of the prioritization methodology with reference to a few SH sections in the State of West Bengal is demonstrated in "Application". Finally, "Conclusion" summarizes the present work and highlights the contribution.

\section{Methodology}

In order to carry out the work, it was necessary to identify techno-economic factors relevant to the prioritization of $\mathrm{SH}$ sections. In the same spirit, it was also necessary to select relevant strategic factors to check the eligibility of $\mathrm{SH}$ sections for different focus area funding schemes. It was then necessary to understand the relative weights of different techno-economic factors in prioritization of $\mathrm{SH}$ sections and develop priority index. The details of these components of work are described in the following sections.

\section{Identification of Techno-Economic Factors}

The prioritization of $\mathrm{SH}$ sections was carried out using several techno-economic factors. Based on review of literature [9, 10] and discussions with experts and policymakers, seven techno-economic factors were identified in the present work. The techno-economic factors included Volume/Capacity ratio (T1), Number of Commercial vehicles per day (T2), Reduction in journey speed (T3), Population directly served by per km road (T4), Growth of Per Capita Income (PCI) in influence area (T5), Growth of Net State Domestic Product (NSDP)/Net District Domestic Product (NDDP) (T6) and potential safety hazards (T7). The techno-economic factors were defined in such a manner that higher the value higher was the priority for improvement.

Volume/Capacity ratio (T1), Number of Commercial vehicles per day (T2), Reduction in journey speed (T3) and Population directly served by per $\mathrm{km}$ road (T4) are the four important factors which characterize the present state of the road section in the context of prioritization. The road safety is a major issue in Indian context and therefore, it was necessary to consider the same during prioritization. It would have been ideal to use the actual accident data on 
different SH sections for this purpose. However, as the accident data were generally not available uniformly for various SH sections, the potential safety hazard were used as a proxy variable. Potential safety hazard was estimated using relevant causal factors for road accidents both from vehicular traffic and pedestrian point of view. Based on experience of carrying out road safety audit on various highways in India and discussions with experts and road authorities, these causal factors were identified as major contributing factors for road accidents in the context of prioritization of SH sections. The causal factors used for estimating the potential safety hazard are mentioned below. As the lengths of different $\mathrm{SH}$ sections are unlikely to be the same, these factors were expressed in number $/ \mathrm{km}$.

1. Presence of major junctions (Project road junction with $\mathrm{NH}, \mathrm{SH}$ and other important roads).

2. Presence of roadside Schools, Colleges, Hospital etc.

3. Presence of built-up areas.

4. Presence of Sharpe curves $(\mathrm{R}<100 \mathrm{~m})$.

5. Presence of Narrow bridge/RUB (less than $7.0 \mathrm{~m}$ width and less than $4.5 \mathrm{~m}$ vertical clearance for RUB).

The likely growth of traffic on different road sections was another important consideration in the context of road prioritization. As a detailed traffic forecast is unlikely to be available at the time of road prioritization, Growth of Per Capita Income (PCI) in influence area (T5) was included as a factor to relate the growth of passenger vehicles and growth of Net State Domestic Product (NSDP)/Net District Domestic Product (NDDP) (T6) was included as a factor to relate the growth of commercial vehicles in influence area of a road section.

In the present work, the data pertaining to Volume/Capacity ratio, Number of Commercial vehicles per day and Reduction in journey speed (T3) were derived from primary surveys. The data pertaining to five factors representing potential safety hazard were also obtained from primary surveys. The data pertaining to Population directly served by per km road, Growth of Per Capita Income (PCI) in influence area and Growth of NSDP/NDDP were derived from secondary sources such as maps, statistical data and Census [11].

\section{Identification of Strategic Factors}

The strategic factors were not directly considered during prioritization of road sections but were instrumental only to identify road sections which qualify for consideration under each focus area of funding scheme. Such identified road sections then may be prioritized using the suggested prioritization methodology. The strategic factors included (1) connectivity to National Highway, (2) connectivity to international borders, (3) present road carriageway width, (4) present surface condition, (5) connectivity to tourist spots, (6) connectivity to industrial hubs and (7) connectivity to backward areas.

District maps with National Highways, State Highways, Tourist spots, Industrial hubs and State/National borders were studied thoroughly to derive the required information related to strategic factors. A SH section was considered to be eligible as providing connectivity to above places if it was directly connecting the place or if it was on the major route to above places while traveling from district headquarter or nearby major railway station.

\section{Importance of Techno-Economic Factors in Prioritization}

After identifying the techno-economic factors, it was necessary to derive relative importance of these factors in prioritization. A survey instrument was designed to collect the importance of these factors in 1 to 5 Likert type ordinal scale ( 1 very less important, 2 less important, 3 moderately important, 4 very important and 5 extremely important) and the data were analyzed using Technique for Order Preference by Similarity to Ideal Solution (TOPSIS) [12] and RIDIT [13]. Although these methods are well established and are available in literature, a brief outline of TOPSIS and RIDIT is given below in the context of the present work.

TOPSIS is one of the well-established multi-attribute decision making methods, first introduced by Hwang and Yoon in 1981 [12]. It provides a best alternative which has shortest distance to the positive ideal solution and farthest distance from the negative ideal solution [14]. While the positive ideal solution composed of all best values possible from the criteria, negative ideal solution consists of all worst values attainable from the criteria [15]. Based on the similarity to the ideal solution, a score is assigned to each alternative and relative weights of the alternatives may be derived from this score.

RIDIT is a useful form of statistical analysis for items involving ratings on a three-or-more-point scale, proposed by Bross in 1958 [16]. The technique is distribution free as it assumes no distribution for the population under study [17]. RIDIT analysis starts with the identification of a population to serve as a standard or reference class. In RIDIT analysis, an average RIDIT value for a class rather than the proportion of respondents giving each of the responses on the dependent variable is calculated [13]. As it was in the case of TOPSIS, a RIDIT score will be assigned to each alternative which has a range that approaches the limits of 0.00 at one end and 1.00 at the other and the relative weights of the alternatives may be derived from the RIDIT score. 


\section{Importance of Causal Factors in Potential Safety Hazard}

In order to estimate the potential safety hazard, it was necessary to calculate importance or relative weights of each causal factors of potential safety hazard. In the present work, a survey instrument was designed to collect data from experts to analyse the same using Analytic Hierarchy Process (AHP) [18]. AHP has been used extensively in various fields and the theoretical background is also available in literature [19-22]. However, a brief outline of AHP in the context of the present work is given below.

AHP is a theory of measurement through pair wise comparisons and relies on the judgments of experts to derive priority scales [23].The technique has been used extensively in calculating relative weights of various alternatives [21, 22]. It includes collection of expert's pair wise comparison on various alternatives on a nine point scale (Saaty's scale) [23]. The pairwise comparison data obtained from the experts were transformed into a standardized matrix and consistency of the responses was checked (to check the degree of randomness in the response) using Eqs. (1) and (2).

$\mathrm{CI}=\left(\lambda_{\max }-\mathrm{n}\right) /(\mathrm{n}-1)$

$\mathrm{CR}=\mathrm{CI} /\{(\mathrm{RI}) \mathrm{n}\}$,

where, $\mathrm{CI}$ is the consistency index, $\mathrm{CR}$ is the consistency ratio, $\mathrm{n}$ is the order of matrix, $\mathrm{RI}$ is the random index, $\lambda_{\max }$ is the principal Eigen value.

After checking the consistency of the responses from the experts, normalized matrix was formed by performing AHP computations on the standardized matrix. Finally, weights of the causal factors were obtained taking the arithmetic mean of rows of normalize matrix.

\section{Development of Priority Index}

After calculating the relative weights of techno-economic factors and causal factors, priority index of each SH section was calculated using the following model.

Priority index, $\quad \mathrm{PI}=\sum \alpha_{\mathrm{i}} \mathrm{T}_{\mathrm{i}}$

where, $\alpha_{i}$ is the relative weight of ith Techno-economic factor, $T_{i}$ is the values for ith techno-economic factor (normalized).

Potential safety hazard was one of the techno-economic factors considered in Eq. (3). In the work potential safety hazard for each $\mathrm{SH}$ section was calculated using the following model.

Potential safety hazard $=\sum \beta_{\mathrm{i}} \mathrm{F}_{\mathrm{i}}$

where, $\beta_{\mathrm{i}}$ is the relative weight of ith causal factor $F_{\mathrm{i}}$ is the number of ith causal factor (per km length).
It may be noted that techno-economic factors have different units and direct adoption of these values would result in priority index dominated by factors having higher numerical values. For instance, V/C values are in the range of $0-1$, whereas commercial vehicle volumes and population served data have their values in the range of thousands. Therefore, prior to the calculation of priority index, technoeconomic factors were normalized to one. In order to express the Priority index values in 1-10 scale for better presentation, expression for scaled priority index was used as given in Eq. (5).

Scaled priority index $(\mathrm{SPI})=1+\frac{9\left(\mathrm{PI}_{i}-\mathrm{PI}_{\min }\right)}{\left(\mathrm{PI}_{\max }-\mathrm{PI}_{\min }\right)}$.

\section{Application}

This section explains the application of the aforementioned methodology with reference to a few SH sections in the State of West Bengal in India. The section includes a brief discussion on various SH sections, collection of primary and secondary data for these sections, collection of rating data and calculation of relative weights of various technoeconomic factors using TOPSIS and RIDIT, collection of data from experts on pair wise comparison of identified causal factors for potential safety hazards and calculation of relative weights of causal factors using AHP and finally, prioritization of selected SH sections using scaled priority index.

\section{Road Sections}

In order to demonstrate the application of the prioritization methodology, $15 \mathrm{SH}$ sections were selected from the State of West Bengal, India. Five sections were selected from $\mathrm{SH}-14$, four sections were selected from $\mathrm{SH}-8$ and $\mathrm{SH}-9$ and two sections were selected from SH-11. All selected highways can be classified as rural highway with intermediate urban/built-up areas. Each road section was assigned a unique section ID. They were SH14-01, SH1401A, SH14-02, SH14-04, SH14-08, SH8-01, SH8-02, SH803, SH8-10, SH9-01, SH9-07, SH9-08, SH9-09, SH11-02, and SH11-07.

\section{Database}

The database for this study was developed as a part of a project initiated by Government of West Bengal for prioritization of $\mathrm{SH}$ sections and improvement of State Highways using various funding sources. In order to obtain data on Commercial Vehicle (CVPD), traffic volume study was conducted as per IRC guidelines [24, 25]. Speed delay survey was conducted using moving car method (4 no. up 


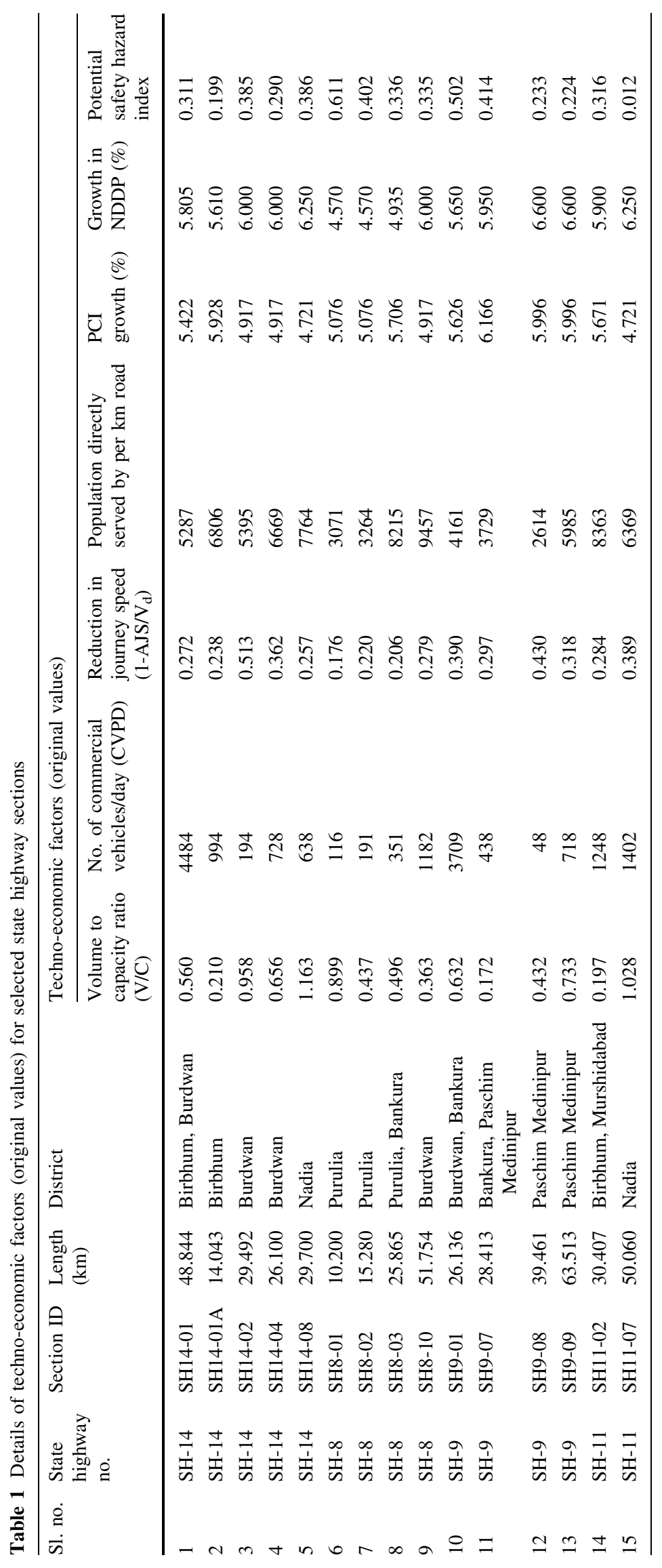




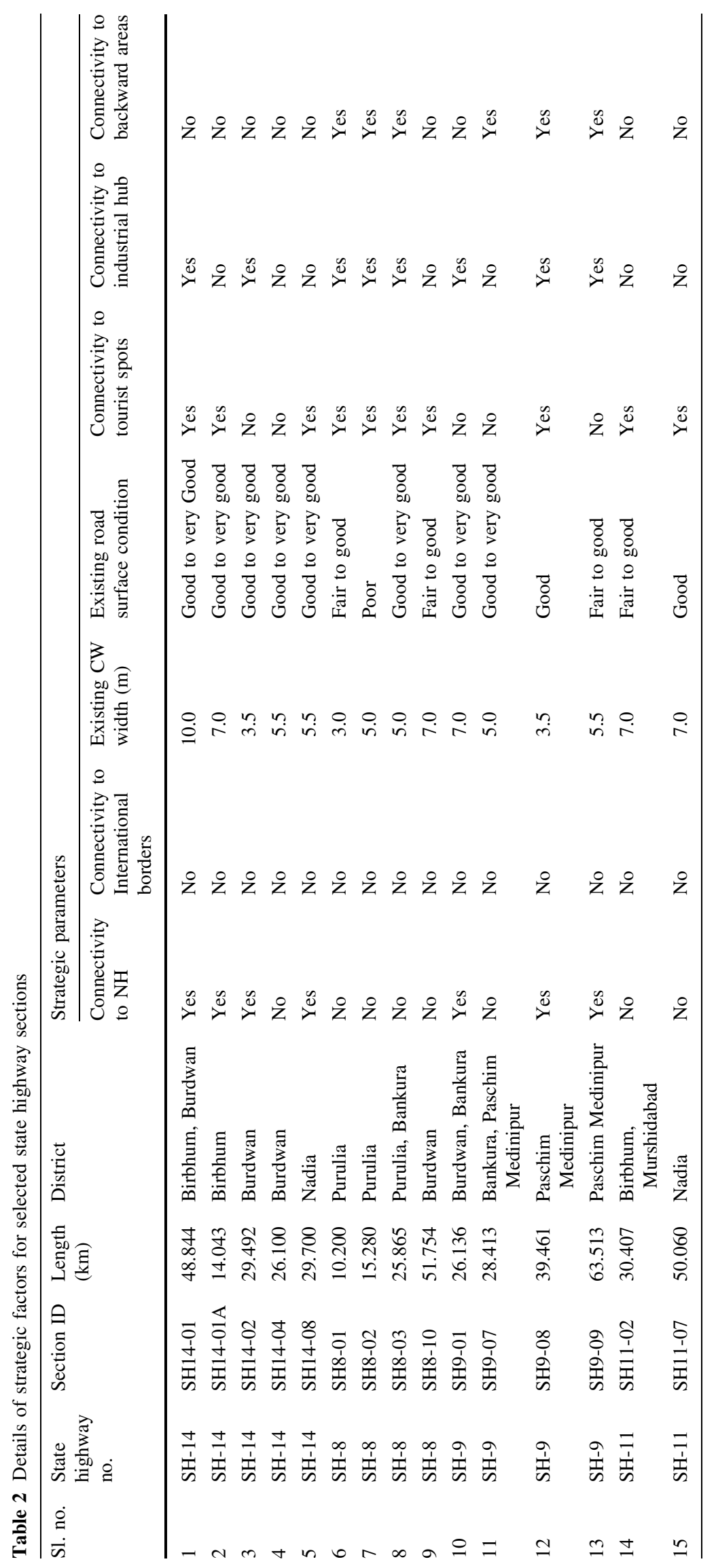


Table 3 Details of TOPSIS and RIDIT analyses

\begin{tabular}{llllll}
\hline Techno-economic parameters & $\begin{array}{l}\text { TOPSIS score } \\
\text { (original) }(1)\end{array}$ & $\begin{array}{l}\text { RIDT score } \\
\text { (original) (2) }\end{array}$ & $\begin{array}{l}\text { TOPSIS score } \\
\text { (normalized) (3) }\end{array}$ & $\begin{array}{l}\text { RIDT score } \\
\text { (normalized) (4) }\end{array}$ & $\begin{array}{l}\text { Relative weight } \\
\text { [average of (3) and (4)] }\end{array}$ \\
\hline Volume/capacity (V/C) ratio & 0.608 & 0.600 & 0.172 & 0.172 & 0.172 \\
No. of commercial vehicles (CVPD)/day & 0.621 & 0.608 & 0.176 & 0.174 & 0.175 \\
$\begin{array}{l}\text { Reduction in journey speed (1-AJS// } \mathrm{d}_{\mathrm{d}} \text { ) } \\
\text { Population directly served by per km }\end{array}$ & 0.435 & 0.451 & 0.123 & 0.129 & 0.126 \\
$\quad$ road of NH/SH in block/district & & 0.535 & 0.525 & 0.150 & 0.151 \\
PCI growth (\%) & 0.445 & 0.403 & 0.126 & 0.115 & 0.121 \\
$\begin{array}{l}\text { Growth in NSDP/NDDP (\%) } \\
\text { Potential safety hazards }\end{array}$ & 0.381 & 0.383 & 0.108 & 0.109 & 0.109 \\
\hline
\end{tabular}

Table 4 Weights of causal factors obtained from AHP

\begin{tabular}{ll}
\hline Causal factor & Relative weight \\
\hline Presence of major junction & 0.279 \\
Presence of roadside school/college/hospital & 0.251 \\
Presence of built-up/market area & 0.246 \\
Presence of sharp curves (R $<100 \mathrm{~m})$ & 0.156 \\
Presence of narrow bridge/RUB & 0.069
\end{tabular}

and down run) to get average journey speed of various sections. Considering land use pattern along State Highways in West Bengal, desired speed $\left(\mathrm{V}_{\mathrm{d}}\right)$ was considered as $65 \mathrm{~km} / \mathrm{h}$. In order to obtain the values for techno-economic and strategic factors, detailed inventory and condition survey were carried out as per IRC guideline [24]. The details of seven techno-economic factors for the selected SH sections are shown in Table 1. Similarly, the details of strategic factors tagged with each selected SH section are shown in Table 2.

\section{Importance of Techno-Economic Factors in Prioritization}

Rating data were collected from officials of road development departments, transportation professionals and experts. Subsequently, the importance/relative weights of various techno-economic factors were analyzed using TOPSIS and RIDIT. The scores obtained from these two analyses were normalized and average of the normalized TOPSIS and RIDIT scores were calculated to obtain the weightage for individual factors.

The results obtained from the analysis using TOPSIS, RIDIT and the derived weightage of various techno-economic parameters are summarized in Table 3. It is interesting to note that the analysis of rating data could bring out variations in the weight of different techno-economic factors in the context of prioritization. At the same time, there is no significant difference in the scores of techno- economic factors obtained from TOPSIS and RIDIT. It was found that 'Commercial vehicles per day' has the maximum weightage (0.175), followed by 'V/C ratio' $(0.172)$, 'population directly served per $\mathrm{km}$ road' (0.151), and potential safety hazards $(0.146)$. On the other hand, 'reduction in journey speed (0.126), 'PCI growth' (0.121), 'growth in NSDP' (0.109) were the techno-economic factors with lesser weights.

\section{Importance of Causal Factors in Potential Safety Hazard}

Potential safety hazard of a road section is considered for both vehicular traffic and pedestrian point of view. In order to calculate the importance of various causal factors in potential safety hazard of a road section, an AHP survey instrument (questionnaire) was designed to collect responses from a panel of experts. The expert panel included traffic engineers, safety engineers and researchers of transportation engineering. The responses collected from experts were checked for consistency and consistent responses were analyzed to obtain weights of various causal factors in potential safety hazards using standard AHP procedure. Results obtained from AHP analysis and the derived weightage for various potential safety hazard factors are summarized in Table 4. It was found that 'presence of major junction' $(0.279)$ has the maximum weightage, followed by 'presence of roadside School/College/Hospital' (0.251) and 'presence of built-up/market area' (0.246). On the other hand, 'presence of sharp curves' $(0.159)$ and 'presence of narrow bridge' $(0.069)$ were the causal factors with lesser weights.

\section{Prioritization of State Highway Sections}

The original and normalized values of techno-economic factors and Priority Index for different SH sections are shown in Tables 2 and 5 respectively. Priority Index of each section was obtained by multiplying normalized 


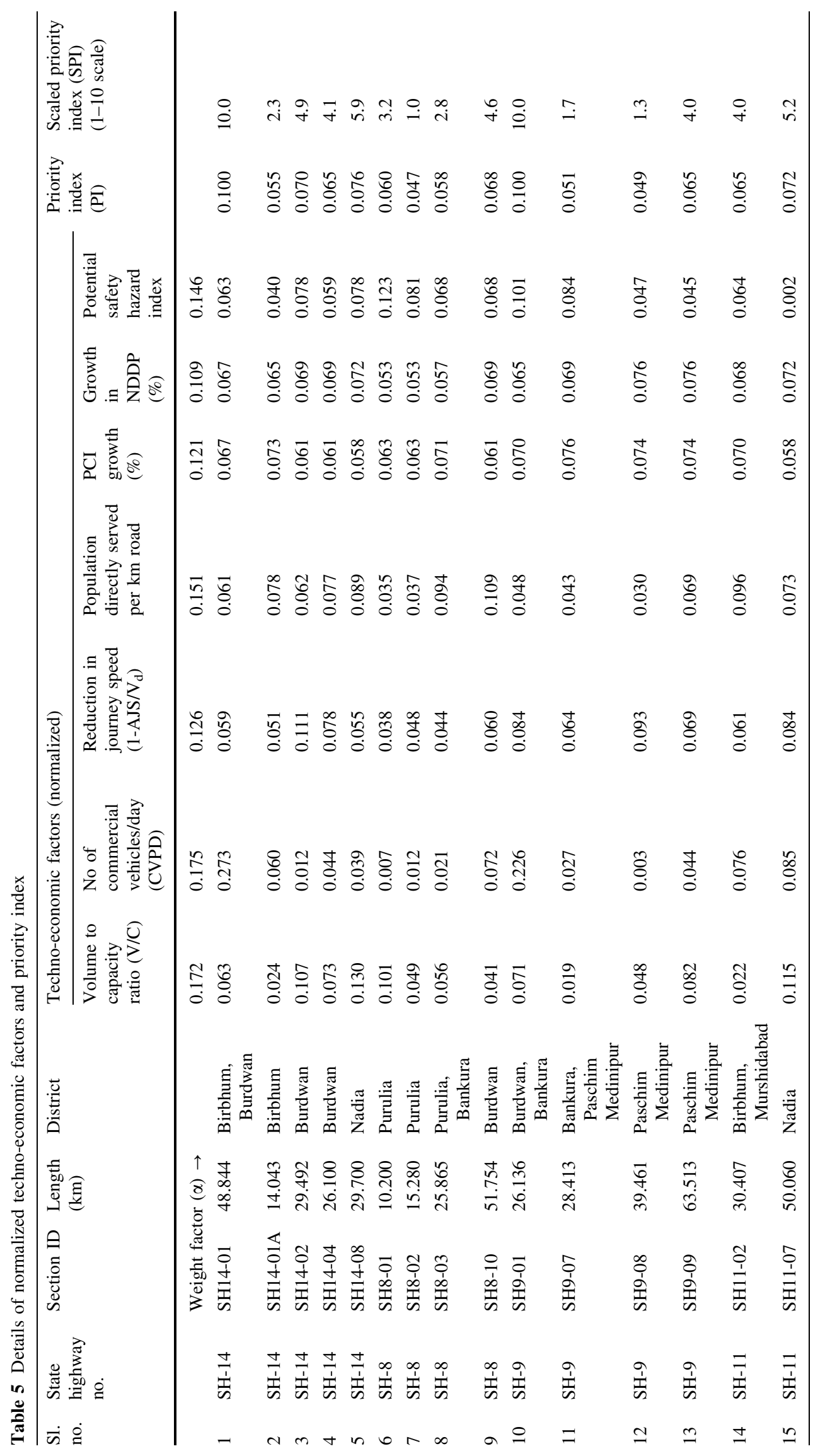


values of techno-economic factors with respective weights using Eq. (3) and it was then scaled using Eq. (5). It may be observed from the table that Sections SH14-01 and SH9-01 have the highest Priority Index $($ SPI $=10)$ while section SH8-02 has the lowest Priority Index (SPI $=1)$.

Using Tables 1, 2 and 5, it is possible to identify sections qualifying for specific funding scheme and prioritize them based on their priority index. For example, if policy makers desire to utilize available fund for backward region development, then Six SH sections, SH8-01, SH8-02, SH803, SH9-07, SH9-08, and SH9-09 are eligible to be considered under the funding scheme. Among the eligible road sections, SH-9-09 and SH8-02 have the highest $(\mathrm{SPI}=4.0)$ and lowest $(\mathrm{SPI}=1.0)$ value of scaled priority index respectively.

\section{Conclusion}

The present paper documents a rational approach for prioritization of State Highway sections and demonstrates its application with reference to selected road stretches in the state of West Bengal in India. The methodology includes identification of techno-economic factors, identification of strategic factors, importance of techno-economic factors in prioritization, importance of causal factors in potential safety hazards and estimation of priority index for road sections.

The methodology was applied successfully with reference to a few SH sections in the state of West Bengal in India. Techno-economic factors and causal factors of potential safety hazards were identified, importance of these factors were calculated through TOPSYS, RIDIT and AHP analysis and prioritization of the $\mathrm{SH}$ sections were carried out based on the scaled priority index. Commercial vehicles per day, Volume to capacity ratio, Population directly served by per $\mathrm{km}$ road and Potential safety hazards were found to be the most important techno-economic factors in prioritization of road sections. Presence of major junctions, presence of roadside School/College/Hospital and presence of built-up/market areas were found to be the most important causal factors of potential safety hazard.

Although the results presented in the paper are case specific, the approach documented in the paper may be modified suitably to prioritize roads in other geographical regions. Also, it would be interesting to calculate the potential safety hazard in the cases where accident data are available and relate the findings with actual accident data.

Acknowledgments Field data collected by RITES Ltd for Strategic Option Study (SOS) initiated by West Bengal Highway Development Corporation Limited (WBHDCL) is used as basic input for technoeconomic factors for prioritizing State Highway section. We convey our sincere thanks to RITES Ltd and WBHDCL for giving us permission for using project data as basic inputs. The authors also acknowledge the opportunity to present the research work that forms the basis of this article at the 3rd Conference of the Transportation Research Group of India (TRG) held at Kolkata (India) from 17 to 20 December, 2015.

\section{References}

1. Chakroborty PK, Agarwal PK, Das A (2012) Comprehensive pavement maintenance strategies for road network through optimal allocation of resources. Transp Plan Technol 35(3):317-339

2. Ahmed NU (1983) An analytical decision model for resource allocation in highway maintenance management. Transp Res Part A 17(2):133-138

3. Fwa TF, Chan WT, Hoque KZ (2000) Multi-objective optimization for pavement maintenance programming. ASCE J Transp Eng 126(5):367-374

4. Ferreira A, Picado-Santos L, Antunes A (2002) A segment-linked optimization model for deterministic pavement management systems. Int J Pavement Eng 3(2):95-105

5. Fwa TF, Chan WT, Tan CY (1996) Genetic-algorithm programming of road maintenance and rehabilitation. ASCE J Transp Eng 122(3):246-253

6. Friesz TL, Fernandez JE (1979) A model of optimal transport maintenance with demand responsiveness. Transp Res Part B 13:317-339

7. Ouyang Y, Madanat S (2004) Optimal scheduling of rehabilitation activities for multiple pavement facilities: exact and approximate solutions. Transp Res Part A 38:347-365

8. Fwa TF, Sinha KC, Riverson JDN (1988) Highway routine maintenance programming at network level. ASCE J Transp Eng 114(5):539-554

9. Maitra B, Azmi M, Ibrahim SN (2002) Prioritization of road projectA Disutility based approach, Transport-XVII, no-2, pp 52-56

10. Dalal J, Mohapatra PKJ, Chandra Mitra G (2010) Prioritization of rural roads: AHP in group decision. Eng Constr Archit Manag 17(2):135-158

11. Statistical Handbook West Bengal (2011) Bureau of Applied Economics and Statistics. Government of West Bengal

12. Hwang CL, Yoon K (1981) Multiple attribute decision making: methods and applications. Springer, New York

13. Hwang CL, Lai YJ, Liu TY (1993) A new approach for multiple objective decision making. Comput Oper Res 20:889-899

14. Sadhukhan S, Banerjee UK, Maitra B (2014) Commuters' Perception towards Transfer Facility Attributes in and Around Metro Stations: Experience in Kolkata. J Urban Plan Dev 141(4):04014038

15. Wang YM, Elhag TMS (2006) Fuzzy TOPSIS method based on alpha level sets with an application to bridge risk assessment. Exp Syst Appl 31(2):309-319

16. Bross IDJ (1958) How to use RIDIT analysis. Biometrics 14(1):18-38

17. Fleiss JL, Levin B, Paik MC (2003) Statistical methods for rates and proportions. Wiley, Hoboken

18. Saaty TL (1980) The analytical hierarchy process. McGraw-Hill, New York

19. Mishra S, Golias MM, Sharma S, Boyles S (2015) Optimal funding allocation strategies for safety improvements on urban intersections. Transp Res Part A 75:113-133

20. Murillo-Hoyos J, Athigakunagorn N, Labi S (2015) Methodology for safety improvement programming using constrained networklevel optimization. Transp Res Part C 50:106-116

21. Mishra S, Khasnabis S (2012) Optimization model for allocating resources for highway safety improvement at urban intersections. J Transp Eng 138(5):535-547 
22. Cheranchery MF, Bhattacharyya K, Maitra B, Boltze M (2016) Assessing safety level of bus stops in the absence of crash data. In: Transportation Research Board 95th Annual Meeting (No. 16-0702)

23. Saaty TL (1995) Decision making for leaders. RWS Publications, Pittsburgh
24. Manual for survey, investigation and preparation of road project (2001) IRC Special Publication No. 19. The Indian Roads Congress, New Delhi

25. Traffic census on non-urban roads (1989) IRC 9. The Indian Roads Congress, New Delhi 